\title{
“ESE DERRAME EXTRAORDINARIO": DETECTIVES POLICIALES, PERIODISTAS Y FALSIFICADORES DE DINERO EN AMÉRICA DEL SUR (AÑOS 1910)
}

\author{
“THAT EXTRAORDINARY SPILL”: POLICE DETECTIVES, JOURNALISTS \\ AND MONEY COUNTERFEITERS IN SOUTH AMERICA, 1910'
}

\author{
Diego Galeano*
}

\begin{abstract}
Este artículo analiza el accionar de detectives policiales sudamericanos en la persecución de redes transfronterizas de falsificación de dinero. En particular, se enfoca en varios viajes a países limítrofes realizados por agentes de las policías de investigaciones a comienzos del siglo XX. Esos desplazamientos permiten examinar la trama de negociaciones que rodeaba la investigación de este tipo de delitos y que involucraba distintos actores (detectives y agentes secretos de la policía, reporteros y corresponsales de la prensa, fabricantes, intermediarios y distribuidores de billetes falsos). Se busca mostrar la estrecha conexión entre ellos: cada una de sus decisiones afectaba los movimientos y márgenes de acción de los demás. Los casos de pesquisas internacionales provocaban desafíos concretos a los redactores de las columnas policiales de la prensa, a los detectives de las agencias de investigación y a los propios integrantes de las redes delictivas.
\end{abstract}

Palabras claves: Falsificación de dinero, Policía de Investigaciones, redes delictivas, América del Sur.

This article analyzes the actions of South American police detectives in the persecution of cross-border counterfeiting networks. Specifically, it focuses on travels undertaken by police investigators to neighbouring countries in the early twentieth century. Such actions allow examination of the negotiation tactics surrounding the investigation of this kind of crime, which involved different social participants: detectives and undercover agents, reporters and press correspondents, manufacturers, dealers and counterfeit money distributors. We seek to examine the close connection between such actors: each individual decision affected the movements and scope of others' reactions. The cases of international investigations created specific challenges to reporters of police chronicles, to the investigation agency detectives and to the members of the criminal networks themselves.

Key words: Counterfeit money, Investigation Police, criminal networks, South America.

\section{Introducción}

Pese al notable crecimiento de la historia social del delito en los últimos años, la falsificación de papel dinero sigue siendo un campo casi completamente inexplorado. Algo más robusta es la historiografía de la falsificación metálica, desde las aproximaciones pioneras de Fernand Braudel (2013: 711-715) y Edoardo Grendi (1987) respecto de la circulación de monedas falsas en el espacio mediterráneo hasta los numerosos trabajos acerca del tráfico atlántico entre la América española y Europa entre los siglos XVII y XVIII (Valenciano 1986; Caporossi 2007; Castro Gutiérrez 2008; Pita Pico 2017). Estos estudios muestran la complejidad de este delito que involucraba cierta división de trabajo entre fabricantes y distribuidores de moneda falsa, así como la porosidad de las fronteras entre las redes de falsificación de dinero y los circuitos de comercio legal.
Las escasas investigaciones concernientes a falsificación de billetes a partir del siglo XIX, período signado por una drástica monetarización de la vida social, sugieren que este delito asumía los rasgos de un mercado ilegal. El negocio de la moneda falsa, estructurado con reglas mercantiles y protagonizado por emprendedores en búsqueda de oportunidades delictivas, ha sido analizado por historiadores como David Johnson (1995) y Randall McGowen (2005). Ambos autores destacan la paulatina preocupación de los gobiernos por el impacto económico del fenómeno delictivo y la inquietud de los bancos emisores por la corrosión de la confianza en los papeles de crédito. Autoridades bancarias y gubernamentales auspiciaron la creación de nuevas agencias de investigación específicamente dedicadas a la vigilancia de las bandas de falsificadores (como, por ejemplo, el Servicio Secreto de Estados Unidos), tendencia global que buscaba centralizar las tareas de persecución y represión de la moneda

\footnotetext{
* Pontifícia Universidade Católica do Rio de Janeiro, Brasil. Correo electrónico: dgaleano@puc-rio.br
} 
falsa. Las agencias de escala nacional buscaban, por un lado, limitar la acción de las autoridades locales, muchas veces sospechadas de negligencia e inclusive de complicidad con los falsificadores, y al mismo tiempo construir espacios de colaboración con policías de otros países. El delito de falsificación de dinero involucraba complejas redes transfronterizas que conectaban distintas regiones y que, en ciertas ocasiones, llegaban a producir en un país billetes falsos de otro, utilizando circuitos de exportadores que los distribuían en el extranjero (Sainz Ortega 1994).

A excepción de algunas aproximaciones puntuales respecto de la ciudad de México (Piccato 2001: 144-148), Santiago de Chile (Palma Alvarado 2011: 104-109) y Río de Janeiro (Chazkel 2011: 159-162), poco se ha investigado acerca de la historia de la falsificación de dinero en América Latina. Aunque ninguno de estos libros se enfoque en la historia de la moneda falsa, aportan pistas para reconocer la existencia de un mercado ilegal con marcada presencia de extranjeros, pautas de negocios que se repetían de país en país, así como una misma división de tareas entre fabricantes, intermediarios y distribuidores. Este artículo no aborda en profundidad esa dimensión del negocio de la falsificación como mercado ilegal, sino que parte de ese punto para abrir otra interrogación: ¿cómo se investigaban estas redes transnacionales de dinero falso con policías locales que, a comienzos del siglo XX, ni siquiera tenían jurisdicción federal?

El caso de las redes de falsificación de dinero permite discutir la enredada trama de las pesquisas más allá de las fronteras, al involucrar al menos tres actores clave: detectives y agentes secretos de la policía, reporteros de la prensa gráfica y, por último, los propios falsificadores y sus cómplices. Esta triangulación estratégica que, en los casos transfronterizos, podía sumar embajadores y corresponsales de los diarios, estaba rodeada de negociaciones y disputas. Cada paso que daba uno de esos actores tenía consecuencias inmediatas para el otro. Se trataba, además, de un mundo en permanente movimiento: circulaciones delictivas de falsificadores y distribuidores que se trasladaban de una ciudad a otra; conexiones policiales que envolvían intercambios de antecedentes, envío de telegramas y viajes de detectives; tráfico de primicias y corresponsalías en un periodismo que también enfrentaba el desafío de construir noticias a la distancia.
El marco temporal se detiene en un momento crucial, cuando las agencias policiales de investigación estaban adquiriendo forma en Argentina, Uruguay, Brasil y Chile, de manera conectada y dialógica. En una tentativa de tornar esos hilos visibles, el artículo analiza dos casos próximos en el tiempo, separados por apenas algunos meses de 1913: un grupo de detectives cariocas que viajaron al Río de la Plata para dar con un atelier de falsificadores y otro de policías argentinos que se trasladaron a Chile con idéntica intención. En ambos casos, el dinero falso no imitaba a los billetes del país donde estaba ubicada la fábrica, sino al de los detectives en tránsito. De todos modos, si el mapa de acción era transnacional, muchos de sus efectos eran estrictamente locales, afectando carreras de periodistas y policías.

Dar cuenta de ese juego de escalas entre la dimensión transnacional y la local es uno de los desafíos metodológicos de este texto. En América del Sur, la historia del delito y de los ilegalismos ha mostrado un reciente interés por las redes delictivas (Ayala Cordero 2010; Galeano 2018). Cuando se trata de redes transnacionales, la mayor parte de los trabajos se concentran en las circulaciones en el espacio atlántico sudamericano, que este artículo aborda en la primera parte. En cambio, pocos estudios han conectado esa dimensión, en un análisis integrador, con las circulaciones trasandinas que serán el objeto de la segunda parte, más allá de la historiografía de las técnicas policiales de identificación (García Ferrari y Galeano 2015; García Ferrari y Palacios Laval 2017). Al final del camino, se vislumbra un mapa de redes, a la vez transatlánticas y transpacíficas, dentro de esta la falsificación de dinero ilumina una densa trama de conexiones delictivas, policiales y periodísticas.

\section{Sherlocks cariocas en el Río de la Plata}

"Encontré flagrante fábrica billetes cinco mil reis gastos mayores dos millones espero dinero Arthur". Este mensaje, sin conectivas ni puntuaciones, llegó por telegrama al jefe de la policía de Río de Janeiro el 22 de mayo de 1913, desde la ciudad de Buenos Aires. Al día siguiente la misma autoridad recibió otro cable de apenas cuatro palabras: "espero hotel Galileo Arthur". Estos telegramas pasarían como dos piezas incomprensibles del archivo policial si no fuera porque están reunidos en una misma carpeta con la carátula "aprensión de moneda falsa" 
y que incluye una carta mucho más rica en detalles (Archivo Nacional de Brasil 1913).

Así es posible saber que Arthur Rodrigues da Silva -remitente de esos cables- era el inspector del Cuerpo de Investigaciones y Seguridad Pública. Había llegado a ese escalafón, que lo dejaba a la cabeza de una estratégica oficina, después de más de diez años de distintos cargos en la policía carioca. Tras su paso por la Policía Marítima, cuando a fines de 1910 el militar Hermes da Fonseca asumió la presidencia de Brasil y designó a Belisario Távora en la jefatura de policía, Arthur Rodrigues quedó al mando de la Guarda Civil y luego, en 1912, del Cuerpo de Investigaciones creado cinco años antes (Samet 2008). A poco de convertirse en su inspector general, aceptó ser entrevistado por un periodista del diario Gazeta de Notícias. Se mostraba crítico del servicio ofrecido por esta oficina que contaba con alrededor de ochenta agentes, a sus ojos mal remunerados y peor preparados. También se quejaba porque los "secretas" (así se llamaba a esos agentes) eran demasiado conocidos en el mundo del delito como para pasar inadvertidos en una misión. Pese a todo, prometía "limpiar la ciudad" de todo tipo de malhechores después de haber logrado, en los tres primeros meses de gestión, detener cerca de cuatrocientos ladrones (Gazeta de Notícias, 27 de mayo de 1912).

En la carta que, un año más tarde, le escribía al jefe de policía explicaba que recién volvía de un viaje a Buenos Aires tras las huellas de una fábrica de moneda falsa brasileña en territorio argentino. El 18 de abril de 1913 el inspector mandó a Buenos Aires un agente secreto ("cuyo nombre Vuestra Excelencia sabe", acotaba Rodrigues), que embarcó desde el puerto de Santos. El agente cumplió con lo pactado y, en los primeros días de mayo, telegrafió avisando que el contacto con el falsificador había sido un éxito. Arthur Rodrigues se disponía a viajar y eligió para acompañarlo a Buenos Aires al coronel Pedro Cámara Campos, que lo había sucedido como inspector general de la Guardia Civil. Al igual que el agente secreto, tomaron un tren a San Pablo para partir desde Santos y así evitar que un embarque en Río de Janeiro despertara sospechas y especulaciones de la prensa. Utilizando nombres falsos, se acomodaron en la primera clase del vapor alemán König Wilhelm II y llegaron a la capital argentina en la noche del 14 de mayo, hospedándose en el Hotel Galileo, mientras que el agente secreto ocupó una habitación en el Hotel Apolo (Archivo Nacional de Brasil 1913).

Pocos días después, Arthur Rodrigues fue a encontrarse con el fabricante de dinero falso, gracias a una cita que le consiguió el agente secreto. El presunto falsificador era Samuel Torner, anarquista catalán, que en 1906 fundó la Escuela Moderna de Valencia, vinculada con los principios de la pedagogía libertaria de Francisco Ferrer. Después de la Semana Trágica de Barcelona y de la condena a muerte de Ferrer en 1909, estos experimentos pedagógicos fueron clausurados por el gobierno español, con algunos de sus directores y maestros detenidos (La Época, Madrid, 10 de octubre de 1909). Tras conseguir un indulto real, Torner terminó migrando hacia Argentina, junto con su esposa, en septiembre de 1909 (AMREC 1909; Caras y Caretas, 23 de octubre de 1909). En Buenos Aires tuvo un papel activo en la fundación de escuelas y en la publicación de periódicos acerca de pedagogía libertaria, como las revistas Francisco Ferrer y La Escuela Popular (Di Stefano 2013: 105-147). Los detectives brasileños parecían desconocer por completo esta trayectoria anarquista de Torner. Al menos, Arthur Rodrigues no hacía ninguna referencia a esa cuestión en su carta a la jefatura policial.

Según su versión, Torner tenía un establecimiento tipográfico en la calle Victoria y allí lo esperaba el catalán para iniciar la transacción de los billetes falsos. La primera negociación, sin embargo, tuvo lugar arriba de un automóvil. Durante el recorrido, por los barrios de Palermo y Belgrano, acordaron que Torney le vendería, en billetes falsos de cinco mil reis brasileños, la suma total de 350 millones de reis, lo que equivalía a cerca de dos mil salarios mensuales del agente secreto que los había presentado. Debía pagar por eso setenta millones de reis, es decir, un quinto del valor nominal en billetes verdaderos, porcentaje promedio en el mercado del dinero falso (Johnson 1995: 59; Palma Alvarado 2011: 105). Ese pago debía hacerse en partes, con una primera seña de cuatro millones, otros treinta millones al momento de mostrar pruebas de la falsificación y, finalmente, los treinta y seis millones restantes cuando se concretara la entrega de la encomienda.

Después de pagar la primera seña de cuatro millones, Arthur Rodrigues agendó el encuentro para ver las pruebas el día 21 de mayo a las ocho de la noche. Según su relato en la carta, combinó con Cámara Campos los pasos a seguir para lograr la 
prisión en flagrante delito y pidió al embajador de Brasil en Buenos Aires (única autoridad que estaba al tanto de la misión) que consiguiera dos agentes subalternos de la policía argentina. Al recibir a los brasileños a la hora combinada, Torner los condujo hasta el fondo del local, atravesó una persiana de metal y los dejó encerrados en la sala de máquinas. El anarquista empezó a imprimir billetes de cinco mil reis, estampándolos de un solo lado del papel y explicó que, para finalizarlos, era necesario esperar que la tinta secara. Mostró su parecido con los verdaderos y exigió el pago de los treinta millones. Arthur Rodrigues se disculpó por no haber traído ese dinero, argumentando que temía que fuera una emboscada de un robo, pero prometió ir a buscarlo al hotel para cumplir con el compromiso.

En aquel momento Torner interrumpió al inspector, empezó a quemar los billetes impresos y a romper la piedra litográfica usada para imprimirlos. El detective se arrojó sobre el falsificador para evitar que eliminara las pruebas, mientras el agente secreto trataba de forzar la puerta y correr a pedir refuerzos. En la calle esperaban Cámara Campos y los policías locales, que al ser avisados ingresaron y detuvieron a Torner. Alrededor de la medianoche, autoridades de la policía argentina llegaron con el juez sumariante para labrar el auto de allanamiento y prisión en flagrante. El supuesto falsificador anarquista fue a parar al calabozo. A primera hora del día siguiente, el inspector le escribía al jefe de policía aquellos telegramas anunciando el triunfo de la misión y pidiendo dinero para cubrir "gastos mayores" que lo esperado. A pocos días de regresar a Brasil, los detectives cariocas dieron testimonio ante el juez federal que intervino en el caso. En ese momento, la prensa brasileña ya anunciaba con fervor el "brillante éxito" de la policía carioca en largas y elogiosas crónicas, generosamente ilustradas con los rostros de los detectives (Imagen 1).

Mediante esos textos es posible reconstruir detalles de la misión que Arthur Rodrigues omitía en su carta a la jefatura. Por un lado, esos reportajes aportan elementos para comprender la pista inicial que condujo a la decisión de embarcar al agente secreto y, más tarde, a los detectives policiales rumbo a Buenos Aires. Circularon dos versiones diferentes, aunque compatibles: ambas apuntaban hacia el Río de la Plata. La primera fue sugerida por el Jornal do Brasil en una crónica precoz, a tan solo dos días del allanamiento en la casa de Torner. Desde 1912, el jefe de la policía argentina, Luis Dellepiane, venía llevando adelante una campaña de deportación de ladrones, cáftenes, anarquistas y otros "indeseables", valiéndose de la ley de expulsión de extranjeros. Los navíos que conducían esos deportados hacían escala en Montevideo, Santos y Río de Janeiro, lo que provocó temor de las autoridades policiales de esas ciudades acerca de posibles desembarcos. En esos meses, los puertos del litoral atlántico sudamericano estaban agitados por la permanente vigilancia de las policías
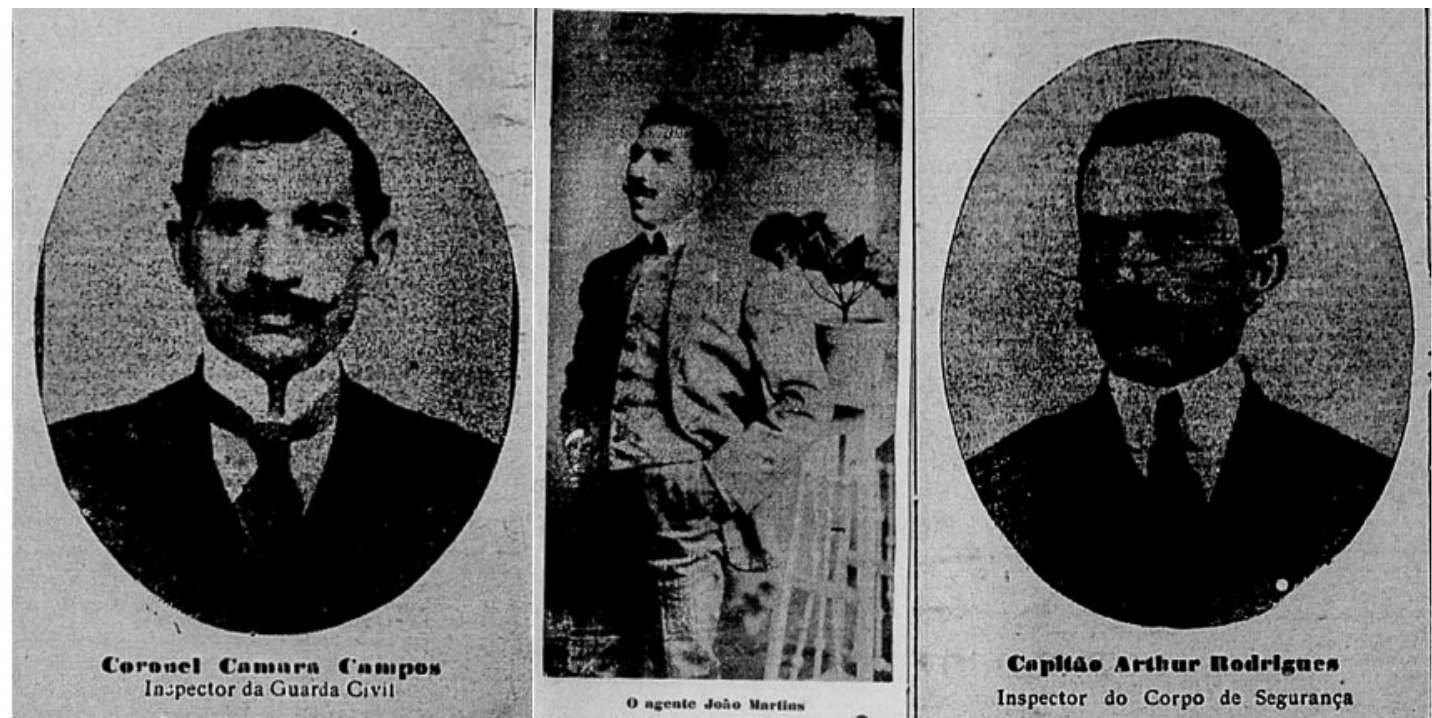

Imagen 1. Retratos de los detectives Arthur Rodrigues, Pedro Câmara Campos y João Martins.

Fuente: Moeda falsa. A polícia carioca na Argentina, Jornal do Comércio, Rio de Janeiro, 2 y 3 de junio de 2013. 
marítimas, cuyos agentes realizaban inspecciones a bordo y controles de documentos (Galeano 2018: 165-173). Según la prensa brasileña, en medio de esa marea de expulsados llegó desde Buenos Aires un sujeto de "estrechas relaciones con los mayores fabricantes de moneda falsa brasilera en aquella República [Argentina]", que terminó usando el recurso de la delación como carta para negociar su estadía en Brasil (Jornal do Brasil, 23 de mayo de 1913). La segunda versión aludía al papel del embajador en Argentina, Luiz Martins de Souza Dantas. Este diplomático, mencionado como colaborador de la pesquisa en la carta de Arthur Rodrigues, habría recibido la denuncia de la existencia de fábricas de dinero falso brasileño y la comunicó al ministro de Relaciones Exterior, quien hizo llegar la inquietud hasta la jefatura de policía (O Paiz, 4 de junio de 1913; A Notícia, 2 de junio de 1913).

Los reportajes de los diarios también iluminaban detalles de la disputa entre la policía y la prensa en torno del problema del secreto de la pesquisa. El Jornal do Brasil, especialmente incisivo en la cacería de primicias policiales, confesaba que había llamado la atención de sus periodistas la repentina desaparición de Rodrigues y Cámara Campos del Palacio de Policía, teniendo en cuenta los altos cargos que ocupaban en el Cuerpo de Investigaciones y la Guarda Civil, respectivamente. Al pedir explicaciones, la jefatura respondió que Cámara Campos había pedido licencia y Rodrigues, cansado de la vida policial, estaba en San Pablo para vender unas tierras de su propiedad con la intención de mudarse a Europa (Jornal do Brasil, 23 de mayo de 1913). Un periodista de otro diario encontró a los detectives en Buenos Aires en medio de las celebraciones del aniversario de la Revolución de Mayo, pocos días después del allanamiento. Cuando les preguntaron el motivo de la presencia en los festejos, respondieron que andaban de paseo en Argentina (A Notícia, 2 de junio de 1913). El éxito de la pesquisa, siempre amenazado por la búsqueda periodística de primicias, dependía de estos recaudos.

Por último, estos reportajes revelaban la identidad del agente secreto que auxilió a los detectives y que Arthur Rodrigues había preferido no nombrar en su carta al jefe de policía. Se trata del "viejo agente João Martins, cuya especialidad era hacer diligencias sobre billetes falsos", mencionaba el Jornal do Brasil (23 de mayo de 1913). Al tiempo que $O$ Paiz, después de felicitar a los inspectores, acotaba: "no sería justo que ocultemos el nombre del viejo agente João Martins, que los acompaña hace tiempo en servicios de esa naturaleza" (O Paiz, 4 de junio de 1913). La alusión recursiva al "viejo agente" adquiere sentidos específicos cuando se observa más allá del caso de Samuel Torner. En efecto, no era la primera vez que Martins se ocupaba de investigar falsificaciones de dinero, ni tampoco su primer viaje al Río de la Plata por este motivo. Desde el comienzo de la jefatura de Belisario Távora, este agente había acompañado a Cámara Campos en misiones realizadas en San Pablo, Montevideo y Buenos Aires. La más resonante tuvo lugar en Uruguay a comienzos de 1911 con la detención del litógrafo Julio Somaschini, hilo de una enmarañada madeja de conexiones entre fabricantes, intermediarios y distribuidores de billetes falsos, con nodos en varias ciudades del espacio atlántico sudamericano (Galeano 2017: 215-220).

La trama del caso que terminó con la prisión de Somaschini en Montevideo tenía una gran similitud con las características del viaje a Buenos Aires, dos años más tarde, para detener a Torner. Los detectives embarcaron rumbo al Río de la Plata vía Santos con nombres falsos y la policía carioca hizo correr el rumor de una exoneración de sus empleados. En Montevideo contaron con la ayuda del embajador brasileño y de la policía local, aunque los contactos con el falsificador se hicieron en forma directa y sigilosa, convocando a las autoridades uruguayas tan solo para el momento del allanamiento y detención en flagrante delito. También en esta ocasión el "éxito" de la pesquisa fue anunciada en la prensa como un triunfo rutilante, en crónicas que bautizaron a Cámara Campos y João Martins como los "Sherlocks cariocas" (Jornal do Brasil, 13 de abril de 1911). Las primeras noticias aparecieron cuando los detectives todavía estaban en Montevideo y siguieron con su retorno a Brasil, que rindió numerosos fotorreportajes. "Ese derrame extraordinario de dinero falso" -escribía un periodista del Correio da Manhã al presentar una larga entrevista con Cámara Campos- provenía de redes delictivas que operaban desde las ciudades del Río de la Plata (Correio da Manhã, 20 de abril de 1911).

La hipótesis del origen rioplatense del dinero falso que circulaba en Brasil se consolidó como lectura preponderante a comienzos de la década de 1910. Recorrió las crónicas de la prensa y se plasmó en el folleto A falsificação dos nossos valores circulantes, publicado en 1912 por el entonces director de la oficina de identificación de la policía de Río 
de Janeiro, Elysio de Carvalho. "El derrame de dinero falso brasileño es colosal", escribía Carvalho en ese texto: "casi todo proviene del extranjero, principalmente de Buenos Aires y de Montevideo, donde existen verdaderas fábricas de moneda falsa" (Carvalho 1912: 7). La pregunta que seguía a esta constatación se refería a los motivos del fenómeno: ¿por qué los falsificadores rioplatenses producían billetes falsos brasileños? El retorno al caso de Samuel Torner y, en particular, a su desenlace, ofrece algunas pistas para una posible respuesta.

La detención de Torner significaba el final del trabajo de los detectives brasileños y el comienzo de la acción de la policía argentina. El caso quedó a cargo de la sección de "Leyes Especiales" de la División de Investigaciones. La oficina debía ese nombre a dos proyectos de ley, sancionados a comienzos del siglo XX, que habían ampliado las prerrogativas policiales en sus ámbitos de injerencia: la ley de falsificación de dinero de 1900 y la ley de represión del juego clandestino de 1902. La vieja Comisaría de Pesquisas creada en el último cuarto del siglo XIX se había transformado en esos años en una compleja estructura dividida en secciones, cada una de estas atesoraba un archivo propio de prontuarios y un plantel de detectives que andaban por la ciudad sin uniforme, portando apenas una tarjeta con su retrato (Laguarda 1914). Muchas de las secciones establecidas ese año-Robos y Hurtos, Defraudaciones y Estafas, Leyes Especiales- devendrían nomenclaturas vitales para la burocracia policial porteña, vigentes a lo largo de todo el siglo XX.

Las grandes falsificaciones de dinero, narradas como obras de maestros en el arte de la fotografía y de las técnicas de reproducción fotomecánicas, tenían tal visibilidad en la prensa que se tornaban un tentador espacio de construcción de celebridad para los agentes de investigaciones. Este sector de la burocracia policial, de salarios más robustos, viajes frecuentes al exterior y, a menudo, recompensas pagadas por los bancos emisores, había devenido un lugar de extensas carreras detectivescas. De hecho, los sucesivos jefes de la Comisaría de Investigaciones (Belisario Otamendi, José Gregorio Rossi, Francisco Laguarda) fueron protagonistas del descubrimiento de fábricas de moneda falsa antes de llegar a la cumbre. El caso Torner cayó en la órbita de la División de Investigaciones que entonces dirigía Rossi, quien lo delegó en el jefe de la sección de Leyes Especiales, el comisario Eduardo Santiago. De acuerdo con la versión de algunos diarios brasileños, el encuentro de los Sherlocks cariocas con el comisario porteño no fue nada amistoso. "¿Usted cree que la policía argentina colabora con los monederos falsos?"-le habría preguntado a Santiago uno de los detectives según el cronista del Jornal do Brasil (3 de junio de 1913). No hubo respuesta y el silencio del interlocutor era leído por ese diario como confirmación de la sospecha: los falsificadores optaban por el dinero extranjero porque, de ese modo, la policía local los dejaba trabajar en paz.

Otros periódicos menos afines a la jefatura de Belisario Távora y más críticos del accionar de su policía de investigaciones narraban este episodio de la misma forma, pero extraían conclusiones diferentes. A Notícia explicaba que el comisario Santiago estaba ofendido por no haber sido avisado de la pesquisa antes del allanamiento y que cumplió con su tarea de auxiliar de la justicia por pura obligación. Este diario buscaba relativizar el "éxito" que los detectives cariocas reafirmaban al regresar el 2 de junio a Río de Janeiro. El clima victorioso de la muchedumbre de periodistas y policías reunidos en el muelle para recibirlos contrastaba con el indefectible cajoneo del caso que se preparaba en Buenos Aires. Samuel Torner declaró ante el juez federal, afirmando que era anarquista pero no falsificador de dinero y que los billetes impresos de un solo lado eran bocetos de un panfleto para repartir en los festejos del 25 de mayo. Inverosímil o no, lo cierto es que las pruebas de la detención en flagrante delito eran tan débiles como fuerte el malestar de la policía argentina respecto de la forma en que fueron obtenidas. "Los diarios rioplatenses no dedicaron una sola línea", observaba con razón el periodista brasileño, lo que llamaba especialmente la atención en un caso que tenía todos los ingredientes de un escándalo atractivo para las columnas policiales (A Notícia, 2 de junio de 1913). Los agentes de investigaciones, informantes de la prensa local, no estaban interesados en que se difundiera una pesquisa de la que podían sacar poco rédito público. En particular, al comisario Santiago no le favorecía en nada un éxito brasileño en su territorio, en medio de una vertiginosa carrera que, pocos meses más tarde, le presentaría su propio desafío transnacional.

\section{Un detective argentino cruza los Andes}

En octubre de este mismo año, la policía de investigaciones de Buenos Aires inició una nueva 
pesquisa para develar el origen de una falsificación de billetes. "Las diligencias efectuadas hasta ahora no han dado resultados favorables", escribía un cronista algo irritado porque los detectives policiales llevaban el caso en sigilo y poco comentaban con la prensa. Por el momento se sabía que los billetes falsos incautados eran de cincuenta pesos y de buena confección, aunque el papel era bastante más grueso que el de los legítimos. Esas "diligencias" incluyeron visitas a distintas casas de cambio, pero la escasez de indicios sobre los fabricantes y circuladores llevó a sospechar que los billetes habían sido fabricados en Europa (La Nación, 18 de octubre de 1913).

A una semana de las primeras noticias, otra versión comenzó a circular en los pasillos policiales y se filtró en la prensa. Quienes hicieron llegar la primicia a los lectores no fueron los reservados agentes de la Comisaría de Investigaciones, que mantenían riguroso silencio, sino los corresponsales en Chile. Sus cables telegráficos llamaban la atención acerca de la pista de una conexión trasandina, que activó redes de colaboración entre las policías de ambos países. Así se supo que el mismísimo comisario Eduardo Santiago había partido rumbo a Chile en el tren trasandino, acompañado por dos inspectores de la sección de Leyes Especiales ( $\mathrm{La}$ Prensa, 25 de octubre de 1913).

Al llegar a Chile, el comisario se entrevistó con el jefe de pesquisas de la capital, Eugenio Castro. Creada en 1896, la Policía Fiscal de Chile estaba dividida en dos secciones: una de orden público que se ocupaba de la vigilancia urbana y otra-llamada Sección de Seguridad-que conducía la investigación de delitos, haciendo de auxiliar de los jueces del crimen. Integrante de una familia de vasta prosapia policial, Eugenio Castro había participado como agente de pesquisas del descubrimiento de un resonante caso de falsificación de dinero en 1898. Ese éxito, entre otros, le allanó el camino hacia la jefatura de la Sección de Seguridad que asumió en 1900 y de la que se retiraría, envuelto en un gran escándalo de corrupción, en 1917 (Hernández Ponce y Salazar González 1994: 91-92). En su encuentro con el comisario argentino, Castro le ofreció instalarse en sus oficinas con todas las comodidades. Desde allí y durante varios días, el comisario Santiago usaba gratuitamente el telégrafo para comunicarse con la jefatura en Buenos Aires e impartía órdenes a sus subordinados, que además de los dos inspectores porteños ahora incluían algunos agentes chilenos puestos a su disposición. "La investigación se hace con todo sigilo, el comisario argentino guarda absoluto incógnito", contaba un corresponsal en Chile, mientras elucubraba conjeturas de una eventual fábrica europea y múltiples rutas sudamericanas (La Nación, 2 de noviembre de 1913). Al fin y al cabo, un punto seguía siendo oscuro para la prensa: ¿por qué la policía de investigaciones de Buenos Aires le había encargado al comisario Santiago esa misión del otro lado de los Andes?

Esta pista chilena, conocida en sus detalles apenas por un pequeño grupo de detectives policiales, pasó a ser explicada a los lectores que seguían el caso. Y eso solo sucedió tras el éxito de un allanamiento y la detención de los supuestos falsificadores. Después de descubrir la fábrica y de avisar al jefe de policía, el comisario Santiago ponía menos obstáculos al flujo de informaciones que llegaban a los diarios. Entonces el público lector supo de los pasos que lo llevaron a cruzar los Andes. El primer billete falso de cincuenta pesos había aparecido en Buenos Aires, en manos de un ingeniero agrónomo chileno, que lo usó para pagar un pequeño consumo en una rotisería. Al ser interrogado por la policía argentina, declaró que lo había obtenido en Santiago, en la casa de cambio de un tal Manuel Rodríguez, situada en la calle Huérfanos, frente al Banco de Chile. Este indicio llevó a los investigadores argentinos a contactarse con la policía chilena, que allanó el negocio de Manuel Rodríguez, sin grandes resultados, aunque quedó detenido por "circulador consciente". Las sospechas se acentuaron cuando se supo que varios artistas de la compañía lírica del teatro Coliseo, que había pasado por Santiago en una gira, volvieron a Buenos Aires con billetes falsos adquiridos en esa misma casa de cambios (Archivo Nacional Histórico 1913).

La investigación fue concentrándose en la huella de un grupo de seis argentinos descendientes de italianos llegados a Chile un año antes. Los hermanos Juan y Vicente Carnevali se habían establecido en una casona de la calle San Pablo, en la localidad de Paine, a cincuenta kilómetros del centro de Santiago. Allí vivían y allí abrieron un almacén de frutos, que la policía sospechaba ser una fachada para esconder la fábrica de billetes falsos. Era, además, un punto de encuentro de los demás sospechosos, acusados de integrar la red delictiva: César Capomasi, Pio Nardi, Antonio Venturi y Miguel Gervasio. Todos fueron detenidos en simultáneo la noche del 3 de 
noviembre de 1913, cuando estaban reunidos en un despacho de bebidas. La misma madrugada se hicieron allanamientos en la casa de la calle San Pablo y en otras propiedades habitadas por los cómplices, pero no se encontró ningún objeto digno de prueba (Archivo Nacional Histórico 1913). A diferencia del accionar de los detectives cariocas en Buenos Aires algunos meses antes, esta vez el allanamiento en la casa de los sospechosos fue realizado bajo orden judicial y con la presencia física del propio juez del segundo tribunal del crimen, Franklin de la Barra. Concluido todo el proceso, el semanario chileno Sucesos consiguió una entrevista exclusiva con el comisario Santiago, quien destacaba la constante presencia del juez en los procedimientos (Sucesos, 13 de noviembre de 1913).

Pese al fracaso inicial, los seis italo-argentinos quedaron detenidos. Por órdenes del comisario Santiago, ni bien la luz del día lo permitió, se iniciaron excavaciones en el patio de la casa de los Carnevali. La experiencia en otros casos de falsificación de dinero le hacía sospechar que podían haber intentado deshacerse de los instrumentos y restos de la fabricación, al conocer las noticias que la prensa venía publicando desde octubre. Bajo el suelo fue encontrado un sello numerador de billetes, frascos de tinta, dos planchas de cobre borradas y otros objetos que complicaban a los hermanos Carnevali. Sin embargo, lo más incriminador eran sus antecedentes penales en Buenos Aires. Cuando el jefe de la policía de investigaciones, José Gregorio Rossi, recibió un extenso telegrama del comisario Santiago con detalles de los resultados de la pesquisa, pudo comprobar que los Carnevali eran "viejos conocidos de la policía" que figuraban en el archivo de prontuarios. La ficha de Vicente mostraba diversas entradas a los calabozos por lesiones y homicidio, mientras que su hermano José tenía antecedentes más vinculados al oficio: en 1899 participó de una falsificación de billetes argentinos en Brasil y en 1902 fue detenido de nuevo por circular billetes falsos (Archivo Nacional Histórico 1913; La Prensa, 6 de noviembre de 1913).

Después de pasar estos datos por telégrafo a su subordinado, Rossi le pidió que iniciara una nueva excavación, con la esperanza de encontrar enterrado el stock de billetes falsos. Aunque no aparecieron, bajo el piso del sótano fueron encontrados los restos de una máquina de impresión "Minerva", además de una maleta con doble fondo "cuidadosamente disimulado", forrado en latón y cubierto de papel
(La Nación, 12 de noviembre de 1913). Eran dos contundentes elementos de incriminación. A comienzos del siglo XX, la compra de una prensa tipo Minerva podía convertirse en motivo para vigilar a un tipógrafo por sospechas de falsificación. La presencia de esta máquina en las páginas de los diarios solía estar tan asociada a la industria de la impresión como a la cuestión del dinero falso. En un caso estrictamente contemporáneo, una falsificación de billetes de diez pesos, la investigación (a cargo de Rossi, quizás por la ausencia del comisario Santiago) "comenzó por averiguar quiénes eran tres sujetos rusos que habían adquirido una Minerva en una importante casa comercial de esta plaza" (La Nación, 22 de noviembre de 1913).

El otro elemento incriminador, la maleta con doble fondo, había sido utilizada por los cómplices para transportar los billetes falsos a diferentes puntos de Chile. De hecho, el hallazgo de la fábrica enterrada en la casa de la calle San Pablo no daba por concluida la investigación. Restaba aún reconstruir las rutas que había seguido la red de distribuidores del dinero falso. Por ese motivo el comisario Santiago viajó a la ciudad de Valparaíso, para encontrar a dos alemanes detenidos por la policía local luego de ser sorprendidos cuando pretendían pasar billetes falsos de cien pesos argentinos. Otras ciudades se iban sumando a la red de complicidades: los alemanes declararon que habían canjeado pesos chilenos por diez mil pesos argentinos en Antofagasta. Entonces, Rossi le pidió al comisario Santiago que extendiera su misión en Chile hasta completar el mapa y detener a todos los fabricantes, intermediarios y distribuidores (La Nación, 7 y 9 de noviembre de 1913).

La nueva sospecha ponía la lupa en una supuesta relación entre los billetes falsos de cincuenta y de cien pesos. El comisario argentino intuía que todos habían salido de la misma fábrica, producidos por los hermanos Carnevali y Capomasi. Por su parte, Pio Nardi, alias Lungo, y Antonio Venturi, alias Rengo, oficiaban de intermediarios y proveedores de los materiales para la falsificación, comprados en una casa de máquinas y tintas de la calle San Antonio, en el centro de Santiago. El dibujante Fleming Weiler era el autor de las planchas de cobre y se encontraba prófugo al igual que el distribuidor Juan Brussa, identificado como responsable por llevar los billetes falsos a la casa de cambios. Según la hipótesis inicial del comisario Santiago, esta banda comenzó con una producción de billetes 
de cien pesos, enviada a Argentina en septiembre de 1913, mes en que apareció en la estación ferroviaria de Retiro una misteriosa valija abandonada con un millón de pesos en billetes falsos de ese valor. Al parecer, el circulador se enteró durante el viaje en tren que la policía estaba investigando el caso y decidió abandonar la valija al llegar a la estación por miedo a ser preso. Este fracaso habría llevado a cambiar la estrategia y fabricar los billetes de cincuenta pesos que más tarde aparecerían en Buenos Aires.

Caso resuelto -pensó Eduardo Santiago- y se dispuso a regresar a Argentina. Cuando anunció su partida, la policía chilena quiso rendirle un homenaje, que el detective esquivó. Tomó el tren trasandino y llegó a Buenos Aires el 14 de noviembre. En días anteriores, los diarios La Prensa y La Nación habían publicado retratos litografiados de los hermanos Carnevali, probablemente sacados de los prontuarios de la policía de investigaciones. Eso se desprende del contraste con las fotografías que el semanario Caras y Caretas publicaría después del regreso del comisario Santiago, en las que se ve a los Carnevali mucho más envejecidos (Imagen 2 e Imagen 3).

Junto con las imágenes de los falsificadores y sus cómplices se mostraban los objetos secuestrados en la fábrica de Chile (el sello numerador, las planchas de cobre, los fragmentos de la máquina Minerva) y un retrato triunfal del comisario Santiago, quien llevó consigo estas fotografías a Argentina. Tras su llegada a Buenos Aires, el diario La Nación (16 de noviembre de 1913) había mencionado que, en la División de Investigaciones, el comisario mostró "muchas fotografías de todos los detenidos y de los objetos secuestrados". El mismo día La Prensa elogiaba la "exitosa misión" del detective policial: "el interés singular de la pesquisa está -escribía el cronista- no solamente en el buen éxito obtenido, sino en haber sido realizada en tierra extranjera, donde ha quedado muy bien sentado el nombre de la policía argentina" (La Prensa, 16 de noviembre de 1913). Lo que estaba en juego no era tanto el prestigio internacional de la policía de Buenos Aires, sino concretamente la carrera de Eduardo Santiago, que aspiraba a los más altos escalones jerárquicos de la Comisaría de Investigaciones. Casos de resonancia pública y visibilidad regional como los de las redes transfronterizas de falsificación de dinero podían ser una bisagra.

El jefe de policía, Eloy Udabe, seguía de cerca sus pasos, dialogaba con su inmediato superior, el ministro del Interior, y también con el ministro de Relaciones Exteriores. La cancillería argentina evaluaba enviar a Chile un pedido de extradición de todos los acusados, que se encontraban procesados en el juzgado de Franklin de la Barra. Este juez les

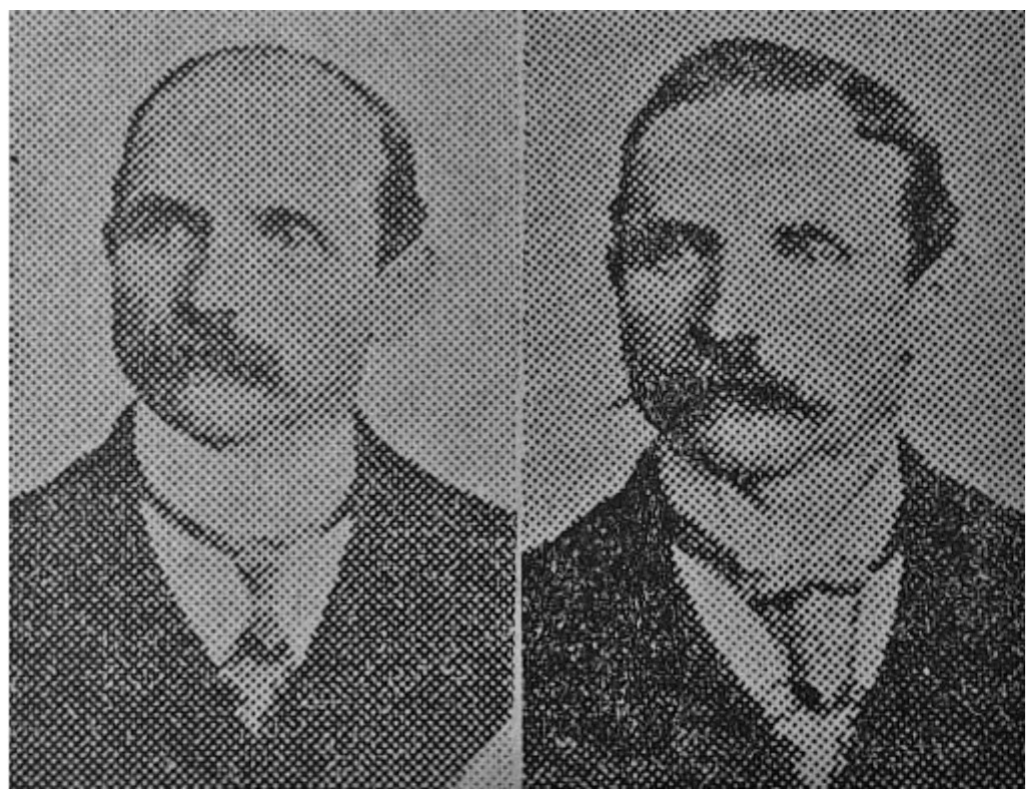

Imagen 2. Retratos de los falsificadores Juan y Vicente Carnevali.

Fuente: Los billetes falsos de 50 pesos. Nuestra policía en Chile, La Nación, Buenos Aires, 6 de noviembre de 2013. 


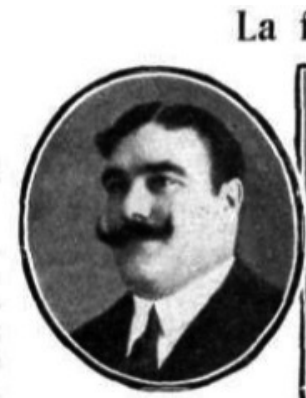

Comisario Eduardo L, Santiago, director de la pesquisa.

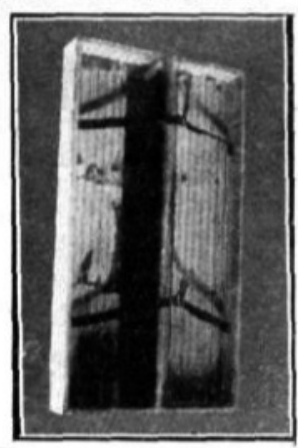

La famosa valija descubierta en Retiro, llena de billetes, y que dió margen a la investi. gación.

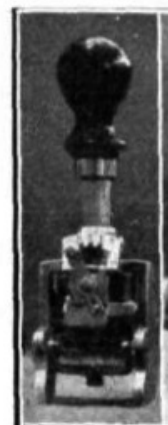

El sello numerador de los falsilicadores.

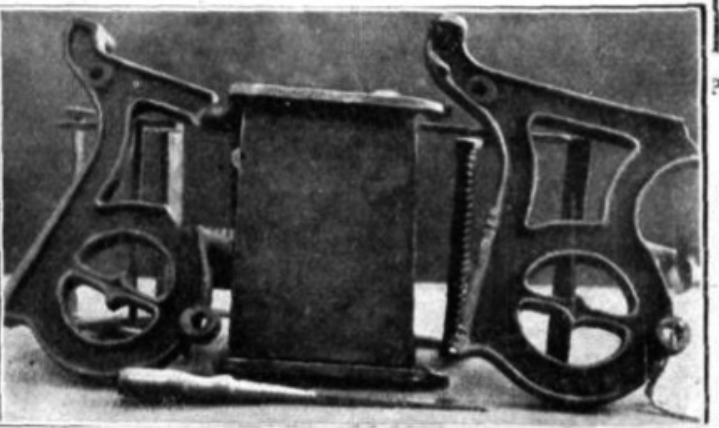

Otro fragmento de la maquinaria de falsificar, encontrado por el comisario Santiago.
Plancha de grabar y trozos de herramientas emplea. cas por los falsifieadores, y que fueron secuestradas.

Conocida por la policia la aparición de hilletes falsos de eineuenta y de cien pesos en esta capital, y sabiendo que la falsifica. ción procedia de Chile, fué eomisionado el comisario Eduardo L. Santiago para trasla. darse allá $y$ esclarecer el hecho. Con los oficiales Diaz y Sinicalde, y auxiliado por la polićáa chilena, encaminó su pesquisa a busear el paradero de los hermanos Carnevali, antiguos profesionales del delito. Después de vigilar a los sospechosos $\mathrm{y}$ al agen. ciero Rodriguez, que aparecía complicado, se allanaron los domicilios sin hallar, en el primer momento, indicios de culpabilidad. No satisfecho el señor Santiago aun, mando hacer excavaciones en el patio de la casa de los Carnevali, encontrándose sepultados bajo una capa de tierra, las herramientas de la minerva empleada por los falsificadores.

Imagen 3. Crónica policial del magazine Caras y Caretas.

Fuente: La falsificación de billetes de 50 y 100 pesos, Caras y Caretas 790, Buenos Aires, 22 de noviembre de 2013.

había dictado prisión preventiva y el embargo de las cuentas bancarias, en las que se suponía -por las fechas de varios depósitos- que había caído el dinero repartido de la falsificación. Pero a fines de noviembre la Corte de Apelaciones les otorgó la libertad bajo fianza y, más tarde, quedaron definitivamente absueltos por falta de pruebas (Archivo Nacional Histórico 1913). Antes de esa noticia, la jefatura de policía decidió encomendar al comisario Santiago una nueva misión, pidiéndole que negociara personalmente las extradiciones. El detective tomó, una vez más, el tren trasandino. El 25 de noviembre llegó a la estación chilena de Los Andes y desde allí se dirigió a Valparaíso ( $L a$ Prensa, 30 de noviembre de 1913 y El Mercurio, 1 de diciembre de 1913).

La prensa chilena contaba que el detective porteño se movía de un lado al otro, de Valparaíso a Los Andes, de allí a Santiago y, días más tarde, a Antofagasta. ¿Por qué el comisario argentino 
recorrería más de mil kilómetros hacia el norte? El destino final era, en realidad, el sur de Perú, donde se sospechaba que se habían refugiado algunos cómplices (El Mercurio, 11 de diciembre de 1913). El inquieto comisario Santiago viajó hasta Lima, se entrevistó con el jefe de la policía de investigaciones y terminó en vísperas de Navidad en un insólito paraje cerca de San Antón, en las serranías de Chilluma. El allanamiento a un rancho rodeado de montañas reveló otro taller de billetes argentinos y así se descubrió que la millonaria falsificación de billetes de cien pesos, aquellos abandonados en la valija encontrada en Retiro, provenían, en realidad, de esta fábrica peruana (La Nación, 17 de diciembre de 1913; Policía de la Capital 1914: 29-30). A comienzos de 1914 los diarios de Buenos Aires anunciaban un nuevo triunfo de Eduardo Santiago, con su retrato ilustrando las crónicas policiales. Los fugitivos alemanes que habían participado de la falsificación en Chile huyeron hacia el norte porque, según la investigación, tenían vínculos con otra red de grabadores e impresores radicados en Lima y dedicados al negocio de los billetes falsos. Una vez más, las fotografías de las maquinarias secuestradas y los retratos de los detenidos atravesaron la cordillera de los Andes para aparecer estampados en las páginas de los diarios argentinos (La Nación, 5 y 16 de enero de 1914).

La conexión entre la falsificación en Chile de billetes argentinos y la fábrica instalada en Perú mostraba que las redes de producción y circulación de moneda falsa involucraban, en América del Sur, sujetos muy movedizos y con lazos de complicidad que abarcaban distintos países. En la memoria anual del Departamento de Policía, elevada al ministro del Interior, Eloy Udabe destacaba la eficacia de la ley contra la falsificación de dinero y del accionar de las autoridades argentinas. Lo que restaba a los delincuentes -decía- era armar fábricas en el extranjero y enviar los billetes falsos a Argentina, pero gracias a la colaboración de las policías de Chile y de Perú se habían logrado neutralizar esas tentativas (República Argentina 1914: 24-25). En los años siguientes, el comisario Santiago seguiría acumulando triunfos detectivescos a la cabeza de la sección de Leyes Especiales y, hacia fines de la década de 1910, de la estratégica sección de Seguridad Personal, que se dedicaba a la investigación de homicidios. Cuando en 1921 el periodista Juan José de Soiza Reilly lo entrevistó para la revista Caras y Caretas, mientras se deshacía en elogios al ya veterano detective escribía: "no es extraño que se le repute como uno de los mejores candidatos para ocupar la jefatura de investigaciones cuando [Francisco] Laguarda se retire" (Caras y Caretas, 14 de mayo de 1921). De hecho, a fines de ese año se cumpliría este presagio.

\section{Conclusiones}

Los “Sherlocks cariocas” que entre 1911 y 1913 viajaron al Río de la Plata tenían mucho en común con el detective argentino Eduardo Santiago. Todos arrastraban una larga trayectoria en las policías de investigaciones, tan larga como permitía la corta historia de esas agencias, que se remontaba a los últimos años del siglo XIX en Buenos Aires y a los primeros del siglo XX en Río de Janeiro. En ese mismo período se crearon también secciones similares en las policías de Montevideo, Santiago de Chile y Lima, que recibieron a los detectives en tránsito. El descubrimiento de fábricas de falsificación de dinero era un trofeo preciado para esos agentes en búsqueda de escalar posiciones en una carrera detectivesca que rendía, al mismo tiempo, tentadores ingresos y notoriedad pública.

En ese camino, el prestigio dentro de la institución, plasmado en reconocimientos de la jefatura y pedidos de ascenso, parecía ser tan clave como la celebridad por fuera de sus pasillos. Por eso se prestaban a entrevistas y reportajes que exponían sus rostros, lo que evidentemente conspiraba contra cualquier tentativa de preservar la identidad para pesquisas secretas. Era un costo que debían pagar para hacer carrera y que los obligaba a usar agentes subalternos encubiertos, así como acudir a soplones del mundo del delito, cuyos nombres y rostros jamás eran difundidos en los diarios. La publicidad de los detectives era, por su parte, la moneda de cambio que los periodistas tenían a mano para obtener primicias, antecedentes, fotografías de los acusados y de los objetos usados para falsificar. Pero la relación entre policía de investigaciones y prensa gráfica no era solamente de reciprocidad: estaba, como queda claro en los casos analizados, atravesada por tensiones y por un siempre delicado equilibrio en torno al problema de preservar el secreto para garantizar el éxito de la pesquisa.

En las misiones al extranjero para desarmar fábricas de moneda falsa nacional, todos estos elementos adquirían una dimensión aún más compleja. 
Los detectives debían negociar con las autoridades locales con el fin de obtener una cobertura legal para los allanamientos y las detenciones de sospechosos. Esa era la única vía para lograr que los falsificadores terminaran presos. Tanto los detectives brasileños como los argentinos regresaron de sus misiones internacionales asegurando a la prensa que habían logrado la tan preciada prisión en flagrante delito y que las evidencias materiales del crimen eran abundantes. Pero ese triunfalismo contrastaba con el resultado final: Torner, los hermanos Carnevali y sus cómplices quedaron libres por falta de pruebas. A pesar de las diferencias en el vínculo entre los policías (tenso entre cariocas y porteños, cordial entre argentinos y chilenos), el corolario judicial fue el mismo. Ese resultado, sin embargo, no impidió que las misiones fueran celebradas y los detectives premiados, porque cuando la absolución fue hecho consumado la prensa ya estaba preocupada con otras cosas.

En estos casos, la presión de la prensa sobre los detectives constituía un obstáculo fundamental, con indagaciones de los periodistas de su propio país, intervención de corresponsales y cronistas del extranjero. El telégrafo era, a la vez, el instrumento de comunicación transnacional de los agentes de investigaciones y un medio de circulación de noticias que, por su velocidad, podían echarlo todo a perder. Es que los integrantes de las bandas de falsificación de dinero también leían los diarios y seguían con atención sus columnas policiales. Cualquier indicio de vigilancia de sus pasos se transformaba en una inmediata destrucción de las pruebas, como quedaba claro en la fabricación de pesos argentinos en Chile. En distintos pasajes del legajo judicial, policías y acusados manifestaban haber leído los reportajes publicados en la prensa de Buenos Aires, Santiago y Valparaíso, a veces para denunciar sus mentiras, otras veces para reforzar la versión construida en la declaración testimonial.

Los detectives, periodistas y falsificadores compartían una misma geografía de conexiones: viajaban en los trenes y barcos por los cuales también circulaban los billetes falsos, las cartas y los periódicos. Las redes de colaboración entre fabricantes, intermediarios y circuladores de dinero falso se comunicaban por los cables telegráficos y por el correo, al igual que los policías y los periodistas. En la documentación analizada conviven numerosos telegramas con cartas intercambiadas por autoridades de diferentes países. Las páginas de los diarios y semanarios ilustrados alternaban, alrededor de un mismo caso, textos de cronistas que observaban in situ el accionar policial con breves noticias telegráficas y cartas de corresponsales en el exterior. De esa manera, diferentes regímenes de circulación de informaciones se superponían en una trama de disputas cotidianas que tenía como protagonistas a los falsificadores, sus cómplices, periodistas, policías, fiscales y jueces. Cada uno jugaba su juego: sus intereses convergían y divergían todo el tiempo.

Policías como Arthur Rodrigues, Pedro Cámara Campos y Eduardo Santiago sabían muy bien que estaban encarnando una figura de enorme atractivo cultural: el detective. En esos años, las ficciones de Maurice Leblanc y Arthur Conan Doyle estaban en la cúspide de su éxito. Los periodistas sudamericanos conocían el interés de sus lectores por las aventuras detectivescas, cuyas traducciones ocupaban con frecuencia el espacio del folletín en los diarios. Además de encantar al público lector, esas ficciones ofrecían un marco de comprensión para las crónicas respecto de delitos "reales", que eran narradas con todos los recursos estéticos de la literatura policial.

Había, no obstante, algunas diferencias significativas con los sabuesos de papel. Lejos del estereotipo del detective privado que resolvía delitos por lógica deductiva y que, en general, despreciaba a los rústicos agentes uniformados, los perseguidores de estas bandas de falsificadores debían mover el cuerpo. Subían y bajaban de carros, trenes y barcos, atravesaban fronteras, forcejeaban con delincuentes, huían de periodistas, pasaban noches en lugares inhóspitos. Y, sobre todas las cosas, encaraban misiones cuyo éxito no dependía del propio convencimiento acerca de la verdad de un crimen, sino de la producción de pruebas suficientes y obtenidas en procedimientos que los tribunales consideraran legales. De lo contrario, el triunfo policial podía devenir fácilmente un fracaso judicial y los supuestos falsificadores -como Torner y los hermanos Carnevali- continuar sus vidas en libertad. 


\section{Referencias Citadas}

Ayala Cordero, I.

2010 Criminales y cómplices: práctica criminal, redes sociales y reproducción de la marginalidad en Santiago, Valparaíso y Buenos Aires, 1890-1910. Tesis para optar al grado de Magíster en Historia, Universidad de Chile, Santiago de Chile.

Braudel, F.

2013 El Mediterráneo y el mundo mediterráneo en la época de Felipe II. Fondo de Cultura Económica, México.

Caporossi, O.

2007 "La falsificación de moneda en la América Hispana a mediados del siglo XVII". Anuario Americanista Europeo 4-5: 65-82.

Carvalho, E.

1912 A falsificação dos nossos valores circulantes. Imprensa Nacional, Rio de Janeiro.

Castro Gutiérrez, F.

2008 "Los falsificadores de moneda en la Nueva España y la justicia del rey". Colonial Latin American Historical Review 17: 301-328.

Chazkel, A.

2011 Laws of Chance: Brazil's Clandestine Lottery and the Making of Urban Public Life. Duke University Press, Durham.

Di Stefano, M.

2013 El lector libertario. Prácticas e ideologías lectoras del anarquismo argentino. Eudeba, Buenos Aires.

Galeano, D.

2017 "Un artista del delito: circulación de dinero falso entre el Río de la Plata y el Brasil, 1899-1911”. En Historia de la cuestión criminal en América Latina, editado por L. Caimari y M. Sozzo, pp. 195-233. Prohistoria, Rosario.

Galeano, D.

2018 Delincuentes viajeros: estafadores, punguistas y policías en el Atlántico sudamericano. Siglo XXI, Buenos Aires.

García Ferrari, M. y Galeano, D.

2015 "Cartografía del bertillonage: circuitos de difusión, usos y resistencias al sistema antropométrico en América Latina”. En Delincuentes, policías y justicias. América Latina, siglos XIX y XX, editado por D. Palma Alvarado, pp. 279-311. Universidad Alberto Hurtado, Santiago de Chile.

García Ferrari, M. y Palacios Laval, C.

2017 "Circulación trasandina de saberes de identificación. Dactiloscopia en Chile, 1893-1909”. Aedos 20: 9-33.

Grendi, E.

1987 "Falsa monetazione e strutture monetarie degli scambi nella Repubblica di Genova fra Cinque e Seicento". Quaderni storici 66: 803-837.

Hernández Ponce, R.; Salazar González, J.

1994 De la policía secreta a la policía científica: Policía de Investigaciones de Chile: 1864-1927. Sección Impr. de la Policía de Investigaciones de Chile, Santiago de Chile.
Johnson, D.R.

1995 Illegal Tender. Counterfeiting and the Secret Service in Nineteenth-Century America. Smithsonian Institution Press, Washington D.C.

Laguarda, F.

1914 La Policía de Investigaciones: su misión, organización y funcionamiento. Imprenta y Encuadernación de la Policía, Buenos Aires.

McGowen, R.

2005 "The Bank of England and the policing of forgery, 1797-1821". Past \& Present 1886: 81-116.

Palma Alvarado, D.

2011 Ladrones: historia social y cultural del robo en Chile, 1870-1920. LOM, Santiago de Chile.

Piccato, P.

2001 City of Suspects: Crime in Mexico City, 1900-1931. Duke University Press, Durham.

Pita Pico, R.

2017 "Por traidor a nuestro Monarca: los falsificadores de monedas y la represión judicial en el Nuevo Reino de Granada”. Historia y Justicia 9: 128-156.

Samet, H.

2008 Construção de um padrão de controle e repressão na Polícia Civil do Distrito Federal por meio do Corpo de Investigações e Segurança Pública (1907-1920). Tesis para optar al grado de Doctor en Historia Social, Universidade Federal do Rio de Janeiro.

Sainz Ortega, L.

1994 "La falsificación de moneda francesa en Barcelona (1879-1882)". Anales de Historia Contemporánea 10: 525-536.

Valenciano, J. C.

1986 "Aspectos de la delincuencia en el siglo XVIII: las bandas de falsificadores de moneda". Cuadernos de Historia Moderna y Contemporánea 7: 33-64.

\section{Fuentes Documentales}

Archivo Nacional Histórico de Chile. 1913. Fondo Judicial Criminal, Caja 939, exp. 11, $2^{\circ}$ Juzgado del Crimen de Santiago contra José Carnevali y otros por falsificación de billetes.

AMREC. 1909. Archivo Histórico del Ministerio de Relaciones Exteriores-Argentina, serie Embajada en Madrid, caja 110.

Archivo Nacional de Brasil. 1913.Fondo GIFI-Secretaría de Policía, Caja 6C 390, $2^{\circ}$ Sección, Aprensión de Moneda Falsa.

Policía de la Capital. 1914. La Policía de Investigaciones: su misión, organización y funcionamiento. Buenos Aires: Imprenta y Encuadernación de la Policía.

República Argentina. 1914. Memoria de la Policía de la Capital, 1913-1914, Buenos Aires, Imprenta y Encuadernación de la Policía. 
